\title{
The Relationship between Identity Styles and Psychological Wellbeing in Sample of College Students
}

\author{
Mohammad Ali Sepahvandi (PhD)
}

Assistance professor of psychology, Lorestan University, Khorram abad, Lorestan, Iran

Abdolvahhab Simin

PhD candidate of psychology, Chamran University, Ahvaz, Khuzestan, Iran

Ali Asghar farokhzadian

Corresponding Author, PhD candidate of psychology, Lorestan University, Khorram abad, Lorestan, Iran

Doi:10.5901/mjss.2016.v7n3s3p207

\section{Abstract}

The purpose of present research was study the relation between identity styles and psychological wellbeing in students of university of semnan. The samples consisted of 256 male-female undergraduate (158 female \& 96 male) in the scholastic year 2009-10 that selected with multi- stage cluster way. Ryff scale of psychological wellbeing (RSPWB), and Identity style Inventory (ISI-6G) used in this research. The relation of identity style and psychological wellbeing evaluate by regression and the difference between them with sexually segregation analyzed with helping independent $T$-test. The results showed that significant positive relationship between normative identity styles and wellbeing and a significant negative relationship between diffuse identity styles and wellbeing. there was no significant difference in none of identity styles and psychological well being in sexually. Thus there is significant relation between between identity styles and psychological wellbeing.

Keywords: Psychological well being, identity style

\section{Introduction}

Different theoretical approaches have been described following the recent studies regarding the nature of psychological well-being (Wising and Eeden, 1997). They identified an overall psychological well-being factor which described it as a combination of special qualities, including coherence, life satisfaction, affect balance and an overall attitude towards optimism or a positive orientation towards life (Roothman, Kristen, Wising, 2003). Psychological well-being was conceptualized in terms of particular components or processes such as emotional processes. According to a careful review of research literature and coherence of developmental theories, mental and clinical health and life survival, Rife (1989)pointed out that these views comprise of identical criteria and psychological health supplements. Theoretical aspects of positive psychological health in recent views include autonomy, environmental mastery, personal growth, positive relations with others, having purpose li life and self-acceptance. The above-mentioned pattern has been widely and extensively studies around the world (Rife \& Singer, 1998; Antonelli, et.al, 1998; Cusullo, et.al, 2006).

Psychological well-being is affected by various issues such as social and familiar relationships, personality and the identity formed within. Identity and psychological well-being are among the issues that have always been emphasized by psychologists, especially in scientific environment such as academic one which true identity formation and health in students studying in is very important.

The term "Identity" is made common from the 1950s. Identity is a social-mental structure that which is first formed in the years before teen. Ericson and other psychologists maintain that the inclination for identity formation is begun from adolescence. Of the main features of identity are selecting values, beliefs and life goals. Identity formation in adolescence is strongly correlated with development of feeling and thoughts, moral growth, emotional growth and self-esteem. Among the factors affecting identity development are personality, family, school and big and small community. Identity is associated with personality traits; flexibility, openness of one's mind and not having bias in dealing with values and beliefs form a matured identity (Bakhshayesh and RezaieMoghadam, 2011). According to Ericson, university provides an opportunity to make help the person in life choices and formation of a stable identity and creates a framework to help 
make decisions, solve problems and deal with everyday problems (Berck, 2007). Identity is a means by which a person can communicate with the community and shows an individual character in a cultural context. People have unique personality traits, but in the meantime, they are also of social and cultural members (Marshal Riow, 2005).

Berzonsky(1990) assumed that individuals are different from each other by different identity conditions make use social-cognitive processes for resolving personal issues, decision-making and the identity formation process. Three styles have been proposed by information processing related to identity by Beronzsky. Theseare Information Style, Normative Style and Confused or Avoidant Style. Research shows that there is a positive relationship between using information identity orientation and self-thinking, problem-solving coping efforts, a strong need for recognition, cognitive complexity, conscious decision-making and consciousness, cheerfulness and openness (Beronzsky, 1990; Beronzsky\& Sullivan, 1992). Shokry, et.al (2006) found in their studies that there is a positive and significant relationship between information identity style and commitment, autonomy, environmental mastery, personal development, shaving positive relationship with others and having purpose in life; there is a positive and significant relationship between normative identity style and commitment and a significant and negative relationship with autonomy and also there is a negative and significant relationship between confused/avoidant identity style and commitment, autonomy, personal development and having goal in life. Therefore, the present study aims to examine the relationship between identity styles and psychological well-being.

\section{Method}

The research community includes all male and female students studying in Semnan University. The study sample was 256 ones out of various faculties of Semnan University which comprise 98 male students and 158 female students who were selected using multistage clustering method. Pearson correlation method was used to determine the correlation between identity styles and psychological well-being, and regression was used to determine the proportion of each identity styles in psychological well-being and the independent $t$ test was used to determine the difference between male and female students.

\subsection{Research Tools}

Psychological Well-Being Scale: This scale was designed by Reef in 1980. Its original form has 120 questions, but shorter forms of 84 questions, 54 questions and 18 questions have also been provided. Psychological well-being scale have 6 subtests namely self-acceptance, having positive relationship with others, self-autonomy, having purpose in life, personal development and mastery over others. In 84-question form, each factor is comprised of 14 questions which the subject is asked to read the questions and mark his/her judgment regarding him/herself with one of the options of completely disagree, somewhat disagree, almost disagree, almost agree, somewhat agree and completely agree. Each question was marked as 1,2,3,4,5 and 6 forms. The higher mark indicates a better psychological well-being.

The validity and reliability of psychological well-being scales has been reported appropriate in various studies. Dierendonol, $\mathrm{D}$ found that the internal consistency of the sub-scales is appropriate and Cronbach's alpha is between 0.77 to 0.90 . Schmutte\&Ryff(1997) reported that the internal consistency of psychological well-being scales is between 0.82 to 0.90. The reliability of the Persian version of this questionnaire in the study performed by Bayani, et al (1999) was reported suitable. Also, Cronbach's alpha was obtained between 0.85 to 0.90 in this study.

Identity Styles Questionnaire (ISI-6G): This questionnaire was made up by Beronzsky (1989) to measure socialcognitive processes applied by children in dealing with identity-related issues. Beronzsky maintains that there are three different orientations or three identity processing style selected by children. Three identity styles are assessed in this questionnaire namely Information Style, Normative Style and Confused/Avoidant Style and have 40 questions of which 11 questions (questions $4,10,19,21,23,28,32,34,40$ ) deal with normative identity style and 10 questions (questions 3,8 , $13,17,24,27,29,31,36,38$ ) deal with confused/avoidant identity style and 10 questions (questions 1, 7, 9, 11, 12, 14, $15,20,22,39)$ also deal with commitment scale. Individuals answered to the questions in a five-grade scale (completely disagree $=1$, disagree $=2$, somewhat agree=3, agree=4, completely agree=5). Questions 9, 11, 14 and 20 are scored inversely. The reliability coefficient for information identity style, normative style,confused/avoidant style and commitment identity are reported $0.75,0.72,0.81$ and 0.85 , respectively by Gaharie, AtefVahid, Dozhkam and Muhammadian (2005) and the reliability coefficient of $0.59,0.64$ and 0.87 are reported for three information identity style, normative style and confused/avoidant style, respectively. 


\section{Results and Discussion}

Table 1: Subject's frequency distribution in terms of gender distinction

\begin{tabular}{|c|c|c|}
\hline Indicator gender & Frequency & Frequency percentage \\
\hline Male & 98 & 38.3 \\
\hline Female & 158 & 61.7 \\
\hline
\end{tabular}

Table 2: mean, standard deviation and maxima ad minima of students

\begin{tabular}{|l|l|c|c|c|c|c|}
\hline Variable & Indicator & Number & Mean & ST & Maximum score & Minimum score \\
\hline \multirow{5}{*}{ Psychological well-being } & Self-acceptance & 256 & 51.10 & 9.96 & 72 & 19 \\
\cline { 2 - 7 } & Self-autonomy & 256 & 55.90 & 7.85 & 73 & 37 \\
\cline { 2 - 6 } & Environmental mastery & 256 & 59.21 & 7.93 & 75 & 37 \\
\cline { 2 - 6 } & Purpose in life & 256 & 59.21 & 7.93 & 75 & 37 \\
\cline { 2 - 6 } & Positive relationships with others & 256 & 59.85 & 10.04 & 80 & 37 \\
\cline { 2 - 6 } & Personal development & 256 & 62.99 & 8.51 & 83 & 45 \\
\hline \multirow{2}{*}{ Identity styles } & Normative & 256 & 35.54 & 4.97 & 44 & 20 \\
\cline { 2 - 6 } & Confused & 256 & 25.74 & 6.31 & 40 & 15 \\
\hline
\end{tabular}

Table 3: tables of correlation coefficient of psychological well-being dimensions and identity styles

\begin{tabular}{|c|c|c|c|c|c|c|c|c|c|c|}
\hline Variable & $\begin{array}{c}\text { Self- } \\
\text { acceptance }\end{array}$ & \begin{tabular}{c|} 
Self- \\
autonomy
\end{tabular} & $\begin{array}{c}\text { Environmental } \\
\text { mastery }\end{array}$ & $\begin{array}{c}\text { Purpose } \\
\text { in life }\end{array}$ & $\begin{array}{l}\text { Positive } \\
\text { relationship } \\
\text { with others }\end{array}$ & \begin{tabular}{c|} 
Personal \\
development
\end{tabular} & $\begin{array}{c}\text { Information } \\
\text { style }\end{array}$ & $\begin{array}{c}\text { Normative } \\
\text { style }\end{array}$ & $\begin{array}{c}\text { Confused } \\
\text { style }\end{array}$ & $\begin{array}{c}\text { Psychological } \\
\text { well-being }\end{array}$ \\
\hline $\begin{array}{l}\text { Self- } \\
\text { acceptance }\end{array}$ & 1 & $0.40^{\star \star}$ & $0.665^{\star \star}$ & $0.552^{\star \star}$ & $0.555^{\star \star}$ & $0.396^{\star \star}$ & $0.208^{\star \star}$ & $0.381^{\star *}$ & 0.047 & $0.798^{\star \star}$ \\
\hline Self-autonomy & - & 1 & $0.430^{\star \star}$ & $0.306^{\star \star}$ & $0.370^{\star \star}$ & $0.515^{\star \star}$ & $0.241^{\star \star}$ & 0.063 & -0.34 & 0.654 \\
\hline $\begin{array}{l}\text { Environmental } \\
\text { mastery }\end{array}$ & - & - & 1 & $0.634^{\star \star}$ & 0.534 & $0.513^{\star *}$ & $0.306^{\star *}$ & $0.342^{\star \star}$ & -0.108 & $0.829^{\star *}$ \\
\hline Purpose in life & - & - & - & 1 & $0.474^{\star *}$ & $0.603^{\star *}$ & $0.357^{\star \star}$ & $0.310^{\star \star}$ & $-0.34^{\star \star}$ & $0.772^{\star *}$ \\
\hline $\begin{array}{l}\text { Positive } \\
\text { relationship } \\
\text { with others }\end{array}$ & - & - & - & - & 1 & $0.476^{\star *}$ & $0.306^{\star \star}$ & $0.189^{\star *}$ & $-0.14^{*}$ & $0.736^{\star \star}$ \\
\hline $\begin{array}{l}\text { Personal } \\
\text { development }\end{array}$ & - & - & - & - & - & 1 & $0.463^{\star \star}$ & $0.125^{\star}$ & $-0.18^{\star \star}$ & $0.753^{\star \star}$ \\
\hline $\begin{array}{l}\text { Information } \\
\text { style }\end{array}$ & - & - & - & - & - & - & 1 & $0.354^{\star *}$ & -0.091 & $0.402^{\star \star}$ \\
\hline $\begin{array}{l}\text { Normative } \\
\text { style }\end{array}$ & - & - & - & - & - & - & - & 1 & $0.126^{\star}$ & $0.0313^{* *}$ \\
\hline Confused style & - & - & - & - & - & - & - & - & 1 & $-0.16^{\star \star}$ \\
\hline $\begin{array}{l}\text { Psychological } \\
\text { well-being }\end{array}$ & - & - & - & - & - & - & - & - & - & 1 \\
\hline
\end{tabular}

The results of Table 3 show that there is a positive and significant relationship between information identity style and psychological well-being $(r=0.0402)$ and a there is a positive and significant relationship between normative identity style and psychological well-being $(r=0.313)$ and there is a negative and significant relationship between confused identity style and psychological well-being $(r=0.162)$.

Table 4: results of determination coefficients and regression coefficients

\begin{tabular}{|l|l|c|c|c|c|}
\hline Criterion variable & Predictor variable & $\mathbf{R}$ & Regression standard coefficient (beta) & $\mathbf{T}$ & $\mathbf{P}$ \\
\hline \multirow{3}{*}{ Psychological well-being } & Normative style & 0.430 & 0.141 & 2.734 & 0.007 \\
\cline { 2 - 7 } & Information style & 0.364 & 0.147 & 2.767 & 0.006 \\
\cline { 2 - 7 } & Confused style & 0.314 & -0.168 & -3.508 & 0.001 \\
\hline
\end{tabular}

The results of regression analysis test in order to determine the power of psychological well-being prediction based on 
identity styles have been presented in table 4 , which indicate that the proportion of each identity style in predicting psychological well-being are different from each other and normative identity style has the highest determination coefficient; that is to say, it can predict the psychological well-being in students more than all other identity styles.

Table 5: distribution of t values in psychological well-being and gender-based identity styles

\begin{tabular}{|c|c|c|c|c|c|c|}
\hline Variable & Gender indicator & Mean & ST & $T$ & Freedom rate & Sig. level \\
\hline \multirow{2}{*}{ Psychological well-being } & Female & 348.43 & 42.54 & \multirow{2}{*}{1.28} & \multirow{2}{*}{217.15} & \multirow{2}{*}{0.201} \\
\hline & Male & 355.14 & 39.54 & & & \\
\hline \multirow{2}{*}{ Information identity style } & Female & 39.18 & 6.28 & \multirow{2}{*}{1.88} & \multirow{2}{*}{223.44} & \multirow{2}{*}{0.061} \\
\hline & Male & 40.06 & 5.60 & & & \\
\hline \multirow{2}{*}{ Normative identity style } & Female & 32.22 & 4.94 & \multirow{2}{*}{1.30} & \multirow{2}{*}{204.211} & \multirow{2}{*}{0.19} \\
\hline & Male & 33.06 & 4.99 & & & \\
\hline \multirow{2}{*}{ Confused identity style } & Female & 26.06 & 6.26 & \multirow{2}{*}{-1.02} & \multirow{2}{*}{201.78} & \multirow{2}{*}{0.30} \\
\hline & Male & 25.22 & 6.42 & & & \\
\hline
\end{tabular}

As the findings obtained in Table 5 shows, there is no statistically significant difference between male and female students' psychological well-being. Also, according to these findings, there is no statistically significant difference between male and female students' information style.

\section{Conclusion}

The results indicate that there is a positive and significant relationship between information identity style and psychological well-being $(r=0.402)$ which this correlation is relatively in a high level; also there is a positive and significant relationship between normative identity style and psychological well-being $(r=313)$ which is relatively in a low level and there is a negative and significant relationship between confused identity style and psychological well-being ( $r=0.162)$ which is in a low level while significant.

The studies performed by GerogiosVelioras and HarkeBosma (2005) and Tomnmy Philips, Joe Pittman (2007) confirm this issue that there is a significant relationship between various identity style and psychological well-being. It is mentioned in studies before that confused/avoidant orientation has a low psychological well-being and information orientation has a high psychological well-being. Normative orientation is related to various forms of psychological wellbeing both positively and negatively (Veliorass and Bassma, 2005).

Confused/avoidant orientation predicts the marks in four psychological well-being scale to go beyond its effects on the prediction loss. According to this notion of orientation (Beronzsky, 1990), this issue refers among other things to this fact that prevaricating and suspending behaviors and making decisions is concerned to low well-being. Two psychological well-being scales (i.e. personal development and self-autonomy) have separate profiles in identity styles. All three identity styles were significant predictors for gaining scores in personal development scale. Those who score higher in information orientation and score lower in normative and confused/avoidant orientations score higher in personal development scale (Villioras and Bassma, 2005). The studies performed before show to some extent an indicative inverse relationship between confused/avoidant orientation and psychological well-being (Philips and Pittman, 2007).

In the study performed by Shokri et.al (2007), the results of correlation matrix indicate that there is a positive and significant relationship between information identity style and psychological well-being scales; and there is a positive and significant relationship between normative identity style and psychological well-being scales (except for autonomy scale which has a negative and non-significant relationship with), and there is a negative and significant relationship between confused identity style and autonomy, environmental mastery, personal development and having purpose in life and also there is a negative and non-significant relationship between scale of having positive relationship with others and selfacceptance.

In the current study, the results showed that a specific coefficient is assigned to each identity styles in regression analysis and this indicate that the proportion of each identity style in predicting psychological well-being are different from each other; that is to say, various identity style cannot predict psychological well-being in a similar fashion. Normative identity style has the most determination coefficient amongst these, i.e. it can predict psychological well-being well higher than all other identity styles.

The results obtained in this study are somehow consistent with the ones obtained in Shokri et.al (2006) mentioned above. Therefore, it can be said that given the although each identity style is significantly related with psychological well- 
being, this issue must be taken into consideration that the prediction power of each identity style for psychological wellbeing are different from each other and none can predict psychological well-being in a similar fashion.

\section{References}

Bakhshayesh, Alireza\&RezaieMoghadam, Marya, (2011), "relationship between religiosity and self-identification and identity formation", Marefat Publications, 20(4), 117-132.

Berck, Lora. A. (2007), "developmental psychology", translated by YahyaSayedMuhammadi, 2008, $2^{\text {nd }}$ edition, Tehran, Arasbaran Publications.

Shokri, Omid; Tajik, Esmaelie; Azizollah , Daneshvarparvar, Zohreh; GhanaieZiba; Dastjerdi, Reza. (2007), "individual difference in identity styles and psychological well-being: the role of commitment", new issues in cognitive sciences, $2^{\text {nd }}$ edition, P. 33-46.

Feyzabadi, Reza. (2005), "comparison of emphatic responses of students in identity styles", MA thesis, Teacher Training University of Tehran.

Marshal, Riow, John. (2005), "motivation and emotion", translated by YahyaSayedMuhammadi, $7^{\text {th }}$ Vol. Tehran, Edited.

Antonelli E, Cucconi L. (1998). Effects of retirement on psychological well- being, the self-concept, and self-esteem. Ricerche Di Psicologia. 22 (3): $27-55$ (in Italian).

Berzonsky, M. D. (1990). Self-construction over the lifespan: A process perspective on identity formation. In G. J. Nieimeyer \& R. A. Neimeyer (Eds.). Advances in Personal Construct Psychology (vol. 1, pp. 155-186). Greenwich CT: JAl.

Berzonsky, M. D. (1998). A self-regulatory model of identity development. Paper presented at the biennial meetings of the Internation Society for the Study of Behavioral Development, Berne, Switzerland.

Berzonsky, M. D., \& Sullivan, C. (1992). Socialcognitive aspects of identity style: Need for cognition, experiential openness, and introspection. Journal of Adolescent Research, 7, 140-155.

Cusullo MM, Castro-Solano A. (2001). Adolescent students' perception of psychological well-being meaning. Revistalbe roamericana Diagnostico Y Evaluasion. 112 (2): 57 - 70 (in Spanish).

Dierendonck, D. (2005). The construct validity of Ryff Scales of psychological well-being and its extention with spiritual well-being. Personality and individual difference. 36,629-643.

Phillips, tommy, M, Pittman, Joe, F. (2007). Adolescence psychological well being by identity style. Journal of Adolescence, 30, 10211034.

Roothman B, Kirsten DT, Wissing MP. (2003). Gender differences in aspects of psychological well-being. South African J Psychol.33 (4): 212-218.

Ryff CD. (1989). Happiness is everything, or is it? Explorations on the meaning of psychological well-being. J Personality Social Psychol. 57: $1069-1081$.

Ryff CD, Singer B. (1998). The contours of positive human health. Psychological Inquiry. 19: 1-28.

Schmutte, P.S., \& Ryff, CD. (1997). Personality and wel- being: reexamining methods and meaning. Journal of Personality and social Psychology, 73,549-559.

Velioras, georgios, Bosma, harke, A. (2005). Are identity style important for psychological well being?. Journal of Adolescence, 28, 397409.

Wissing MP, Van Eeden C. (1997). Psychological well-being: A fortigenic conceptualization and empirical clarification. Paper presented at the 3rd Annual Congress of the Psychological Society of South Africa, Durban, South Africa. 